\section{OPEN ACCESS}

Edited by:

Michael P. Meyer,

Middlemore Hospital, New Zealand

Reviewed by:

Salvatore Andrea Mastrolia, Ospedale dei Bambini Vittore Buzzi,

María Gormaz,

Agencia Valenciana de Salud, Spain

*Correspondence:

Stefano Ghirardello

stefano.ghirardello@mangiagalli.it

Specialty section:

This article was submitted to Neonatology,

a section of the journal

Frontiers in Pediatrics

Received: 01 August 2018 Accepted: 13 November 2018 Published: 03 December 2018

Citation:

Ghirardello S, Di Tommaso M, Fiocchi S, Locatelli A, Perrone B, Pratesi S and Saracco P (2018) Italian Recommendations for Placental

Transfusion Strategies.

Front. Pediatr. 6:372

doi: 10.3389/fped.2018.00372

\title{
Italian Recommendations for Placental Transfusion Strategies
}

\begin{abstract}
Stefano Ghirardello ${ }^{1 *}$, Mariarosaria Di Tommaso ${ }^{2}$, Stefano Fiocchi ${ }^{3}$, Anna Locatelli $^{4}$, Barbara Perrone ${ }^{5}$, Simone Pratesi ${ }^{6}$ and Paola Saracco ${ }^{7}$

${ }^{1}$ Neonatal Intensive Care Unit, Department of Clinical Sciences and Community Health, Fondazione IRCCS Cà Granda Ospedale Maggiore Policlinico, Milan, Italy, ${ }^{2}$ Health Sciences Department, University of Firenze, Careggi University Hospital, Florence, Italy, ${ }^{3}$ Neonatology and Neonatal Intensive Care Unit, ASST Grande Ospedale Metropolitano Niguarda, Milan, Italy, ${ }^{4}$ Obstetrics and Gynecology Unit, School of Medicine and Surgery, University of Milano Bicocca, Milan, Italy, ${ }^{5}$ Division of Neonatology and NICU, Salesi Children's Hospital, Ancona, Italy, ${ }^{6}$ Neonatology Unit, Careggi University Hospital, Florence, Italy, ${ }^{7}$ Department of Pediatric Sciences, Azienda Ospedaliero-Universitaria Città della Salute e della Scienza di Torino, Turin, Italy
\end{abstract}

At delivery, if the cord is not clamped, blood continues to pass from the placenta to the newborn during the first minutes of life, allowing the transfer of $25-35 \mathrm{ml} / \mathrm{kg}$ of placental blood to the newborn, depending on gestational age, the timing of cord clamping, the position of the infant at birth, the onset of respiration, and administration of uterotonics to the mother. However, deriving benefits from delayed cord clamping (DCC) are not merely related to placental-to-fetal blood transfusion; establishing spontaneous ventilation before cutting the cord improves venous return to the right heart and pulmonary blood flow, protecting the newborn from the transient low cardiac output, and systemic arterial pressure fluctuations. Recent meta-analyses showed that delayed cord clamping reduces mortality and red blood cell transfusions in preterm newborns and increases iron stores in term newborns. Various authors suggested umbilical cord milking $(U C M)$ as a safe alternative when delayed cord clamping is not feasible. Many scientific societies recommend waiting 30-60 s before clamping the cord for both term and preterm newborns not requiring resuscitation. To improve the uptake of placental transfusion strategies, in 2016 an Italian Task Force for the Management of Umbilical Cord Clamping drafted national recommendations for the management of cord clamping in term and preterm deliveries. The task force performed a detailed review of the literature using the GRADE methodological approach. The document analyzed all clinical scenarios that operators could deal with in the delivery room, including cord blood gas analysis during delayed cord clamping and time to cord clamping in the case of umbilical cord blood banking. The panel intended to promote a more physiological and individualized approach to cord clamping, specifically for the most preterm newborn. A feasible option to implement delayed cord clamping in very preterm deliveries is to move the neonatologist to the mother's bedside to assess the newborn's clinical condition at birth. This option could safely guarantee the first steps of stabilization before clamping the cord and allow DCC in the first $30 \mathrm{~s}$ of life, without delaying resuscitation. Contra-indications to placental transfusion strategies are clinical situations that may endanger mother 's health and those that may delay immediate newborn's resuscitation when required.

Keywords: delayed cord clamping, preterm newborn, umbilical cord milking, neonatal resuscitation, recommendation, cord blood banking, twin, HIV pregnancy 


\section{INTRODUCTION}

Until 1960, delayed umbilical cord clamping (DCC) to promote placental transfusion was common; afterward, cord clamping immediately after birth became standard practice to reduce the risk of postpartum hemorrhage, although without evidence $(1,2)$. In the last decade, great interest has been renewed on DCC and umbilical cord milking (UCM), an active maneuver by which the content of the umbilical cord is gently squeezed toward the newborn (3).

Both techniques, referred in the text as placental transfusion strategies, allow transferring a similar amount of fetal blood, between 25 and $35 \mathrm{ml} / \mathrm{kg}$, from the placenta to the newborn, increasing neonatal volemia, hemoglobin concentration, and blood pressure in the first days of life (4-6).

The amount of blood transferred to the newborn during DCC depends on various factors: the time of cord clamping, the mode of delivery, the position of the newborn, the beginning of spontaneous breathing and respiration, and uterine contractions (7). The ideal timing of cord clamping is likely different for every newborn, depending on how rapidly pulmonary vascular resistances reduce and placental blood fills the pulmonary vascular bed. Indeed, various researchers underlined how cord clamping should be individualized for each newborn (8-10).

Milking the umbilical cord is considered a valid alternative to DCC, as it takes $10-20 \mathrm{~s}$ to be performed, allowing rapid neonatal resuscitation when required. It consists of squeezing gently $20-30 \mathrm{~cm}$ of umbilical cord three to five times from the placenta to the newborn at a velocity of $10 \mathrm{~cm} / \mathrm{s}(3,5,11)$. This maneuver could be carried out when the cord is intact (connected to the placenta) or after it is cut and separated from the placenta (c-UCM) (12). The combined intervention of DCC followed by UCM (13) showed a positive cumulative effect on neonatal hematological parameters in the first weeks of life, compared to DCC or UCM only, without side effects.

\section{Placental Transfusion Strategies and Neonatal Outcomes}

In the last years, research studies and meta-analysis highlighted the favorable impact of placental transfusion strategies on shortterm neonatal outcomes. Both have been associated with a lower incidence of iron deficiency at 3-6 months in term newborns (14-16). In preterm newborns DCC and UCM were associated to higher arterial blood pressure and hemoglobin at admission, reduced need for red blood cell transfusions, reduces incidence of intraventricular hemorrhage (IVH), lateonset sepsis, necrotizing enterocolitis (NEC), and mortality (1723). Umbilical cord milking in newborns with gestational age $<33$ weeks reduced the risk of bronchopulmonary dysplasia and intraventricular hemorrhage (11). The most recent results deriving from a multicenter trial (APTS) (24) that enrolled

Abbreviations: BPD, Bronchopulmonary dysplasia; CD, Cesarean Delivered; CHD, Congenital hearth defect; CS, Cesarean Section; DCC, Delayed Cord Clamping; GA, Gestational Age; ICC, Immediate Cord Clamping; IVH, Intraventricular Hemorrhage; NEC, Necrotizing Enterocolitis; UCM, Umbilical Cord Milking; c- UCM, cut-cord Umbilical Cord Milking; VD, Vaginal Delivery; WHO, World Health Organization. to delayed or immediate clamping more than 1,500 preterm newborns with gestational age $<30$ weeks failed to demonstrate differences in death or major morbidity (severe brain injury, severe retinopathy of prematurity, necrotizing enterocolitis, or late-onset sepsis) between DCC and early clamping. The same working group, however, in the subsequent meta-analysis of 18 controlled trials (25) concluded for a strong and significant association between DCC and reduced hospital mortality, both in preterm and extreme preterm infants and confirmed a significant reduction in red blood cell transfusions.

The reported long-term effects of placental transfusions are still scarce; a recent neuro-cognitive follow-up study of term newborns associated DCC to improved fine motor and social domains scores at 4 years of age, particularly in males (26). Umbilical cord milking in preterm newborns was associated to higher language and cognitive scores at 2 years of corrected age compared to DCC (27).

\section{Placental Transfusion Strategies and Neonatal Resuscitation}

Recent studies on animal models $(28,29)$ showed that DCC promotes a smoother cardiopulmonary transition at birth. Indeed, if the cord is clamped immediately, left ventricle suddenly loses the source of its filling, and the left ventricle preload becomes fully dependent on pulmonary venous return from the lungs. Pulmonary blood flow increases slowly after birth as the newborn starts breathing. This period between cord clamping and the onset of breathing is called "non-respiring interval," during which hemodynamic fluctuations associated with reduced cerebral oxygenation have been demonstrated in animals (29). Otherwise, if the cord is maintained unclamped, blood coming from the placenta through the umbilical vein continues to fill left ventricle, while the onset of newborn's ventilation increases pulmonary blood flow and venous return (29). Thus, delaying cord clamping until after the start of breathing would maintain left ventricle pre-load unchanged, as demonstrated by the absence of hemodynamic fluctuations in animal models (28).

Scientific societies and neonatal resuscitation guidelines (3034) suggest delaying the clamping of the cord by $30-60 \mathrm{~s}$ in vigorous preterm infants and by $3-5 \mathrm{~min}$ in term newborns not requiring resuscitation but recommend immediate cord clamping for apneic or limp newborns at birth $(31,32)$.

Therefore, "newborns requiring resuscitation" have been excluded by most research protocols and a significant percentage of infants included in DCC trials were clamped earlier than scheduled, mostly due to clinical concerns about delaying ventilation in non-vigorous infants $(19,24,35-38)$. The observation by Nevill et al. (36) that preterm newborns not breathing during DCC were more likely to be intubated, have chronic lung disease, and severe intraventricular hemorrhage compared to breathing infants, underlines the importance of promoting spontaneous breathing during DCC.

When stimulation of the newborn occurs before clamping the cord, as suggested by WHO guidelines (30), most term and preterm infants start breathing spontaneously within the first minute of life (39-41). 
A feasible option to promote placental transfusion in the most compromised newborns is to provide neonatal resuscitation during DCC. Recently Katheria et al. (41) randomized newborns with gestational age below 32 weeks to receive NCPAP or positive pressure ventilation during DCC $\geq 60 \mathrm{~s}$ or to receive DCC only; this latter group, if apneic, was dried and stimulated until the onset of spontaneous breathing. The authors demonstrated that there was no significant difference in the time from birth to the first spontaneous respiratory act between the two cohorts; $\sim 90 \%$ of newborns in both groups spontaneously breathed before clamping the cord. The use of CPAP or ventilation in the first $60 \mathrm{~s}$ of DCC, had no effect on placental transfusion, physiological variables in the first $24 \mathrm{~h}$ of life, or neonatal outcomes when compared with stimulation alone.

Umbilical cord milking could offer an advantage over DCC in preterm newborns who are deemed too unstable to wait for DCC and who are at the highest risk of severe IVH and death. Compared to DCC, UCM have been associated with higher blood pressure in the first day of life (35). However, recent resuscitation guidelines (32) suggested against its routine use in preterm newborns with a gestational age lower than 29 weeks.

\section{The Umbilical Cord Clamping Project}

A recent Italian survey (38) showed a wide variation among operators in the management of cord clamping, especially at the lowest gestational ages, where only $10 \%$ of the responders declared to perform DCC. Milking was the preferred technique to allow placental transfusion in the case of extreme prematurity, resuscitation need and cesarean delivery.

The study showed a significant correlation between the implementation of DCC and UCM and the knowledge of related benefits, the availability of obstetric-neonatal guidelines and the engagement across professions within the delivery team.

In 2016 the Italian Task Force for the Management of Umbilical Cord Clamping has been constituted to draft recommendations for the management of cord clamping in term and preterm newborns.

The aim of this document (first edition) is to provide operators involved in childbirth assistance with an updated consultation tool for optimal management of umbilical cord clamping in term and preterm newborns to standardize placental transfusion strategies in different clinical scenarios. Attention was paid to the application of DCC and UCM in extremely premature infants, according to guidelines for newborn's resuscitation $(31,32)$.

Preterm deliveries are classically categorized, depending on gestational age at birth, in extremely preterm ( $<28$ weeks), very preterm ( $<32$ weeks), moderate $(32-33+6 / 7$ weeks), and late preterm $(34-36+6 / 7$ weeks $)$ birth.

Available studies on placental transfusion strategies, however, showed a significant overlap among these categories. For this reason, the panel decided to elaborate recommendations tailored to a unique group of patients that included extreme, very and moderate preterm newborns for whom immediate post-partum medical assistance was expected. Late preterm newborns have been considered separately because, in most cases, they do not necessitate medical interventions at birth, except for the presence of a skilled operator in neonatal resuscitation, as recommended by resuscitation guidelines in 2010 (42).

\section{MATERIALS AND METHODS}

The working group consists of obstetricians, midwifes, and neonatologists with experience in delivery room resuscitation, neonatal hematology, and cardiology, belonging to the Italian Society of Neonatology (SIN), the Italian Society of Perinatal Medicine (SIMP), and the National Federation of Midwifes (FNCO).

The Italian version of the document derives from a detailed review of the English literature until December 2017 and a summary of the recommendations already published on the subject by scientific societies and expert panels. Articles' search was performed in 2 online databases (PubMed and the Cochrane Library).

Recommendations have been drawn using the methodological approach proposed by the Grading of Recommendations, Assessment, Development and Evaluation (GRADE) Working Group (43).

After identification and prioritization of the questions to be addressed, articles were screened for further evaluation. GRADE is a consensus process that rates the quality of evidence and strength of recommendations along with values and preferences. The quality of the evidence (or confidence in the estimate of the effect) was categorized as high (where one has high confidence in the estimate of effect as reported in a synthesis of the literature), moderate (where one has moderate confidence, but there may be differences from a further elucidated truth), low (where one has low confidence in the estimate of the effect that may be substantially different from the true effect), or very low (where it is possible that the estimate of the effect is substantially different from the true effect) (44, 45).

Recommendations were based on the evaluation of the expected benefits and risks connected to placental transfusion practices and the clinical context in which they could be applied. The safety for the mother and the newborn guided the drafting of the recommendations when evidence from the literature was not conclusive. The panel discussed and approved each statement unanimously during quarterly meetings held between 2016 and 2017.

The original document has been externally reviewed and accepted by a panel of neonatologists, obstetricians, and midwifes (see Acknowledgment).

Quality of evidence and strength of recommendations are summarized in Table $\mathbf{1 .}$

\section{Delayed Cord Clamping in Vaginally Delivered Term Newborn}

The meta-analysis by McDonald et al. (14) demonstrated that DCC (various definition: 1 to $5 \mathrm{~min}$ after birth, when cord stop pulsing, after placental descending) improves hemoglobin concentration at birth [3 studies, ( RR $-2.1795 \% \mathrm{CI}-4 /-0.28)$ ], iron stores at 3-6 months of age [(5 studies) RR 2.65; 95\% 
TABLE 1 | Quality of evidence and strenght of recommendations.

\begin{tabular}{ll}
\hline QUALITY OF EVIDENCE & \\
\hline High quality & A \\
Moderate quality & B \\
Low quality & C \\
Very low quality & D \\
STRENGTH OF RECOMMENDATIONS & 1 \\
Strong recommendation: the desirable effects of \\
$\begin{array}{l}\text { adherence outweigh the undesirable effects } \\
\text { Weak recommendations: the desirable effects of } \\
\text { adherence probably outweigh the undesirable effects, } \\
\text { although the trade-offs are uncertain }\end{array}$
\end{tabular}

CI 1.04-6.73], and birth weight [(12 studies) RR -101.2; 95\% CI -158/-44)]. Andersson et al. (46) demonstrated that $3 \mathrm{~min}$ DCC improved ferritin concentration (117 vs. $81 \mathrm{mcg} / \mathrm{l}, p<0.001)$ and reduced the prevalence of iron deficiency (0.6 vs. $5.7 \%, p<0.01$ ) at 4 months of age in a population where the prevalence of iron deficient anemia is low.

These positive results last up to the end of the first year of life in the case of infants born to mothers with low serum ferritin concentration at delivery $(47,48)$. Ashish et al. (48) demonstrated in a large Nepalese cohort of 540 infants that 3-min DCC reduced the prevalence of anemia and the risk of iron deficiency (RR 0.58; $95 \%$ CI $0.44-0.77$ ) at 8 months of life. Hemoglobin concentration was significantly higher until the end of the first year of life in the DCC group compared to early clamping.

The position (relative to perineum) of the newborn during DCC did not seem to affect the volume of placental transfusion (49) but a recent trail associated the lower position of the newborn to a more efficient placental transfusion (50). Most of the available studies $(14,46,51)$ compared various delayed clamping times (from 1 to $5 \mathrm{~min}$ or until cord pulsation) to ICC, and evaluated different hematological parameters. These researches unanimously concluded for a positive effect of DCC on iron stores and a possible contribution to improved fine motor performances and social domains at 4 years of age, especially in males (26). In term newborns not requiring immediate resuscitation, delayed clamping for at least $60 \mathrm{~s}$ is recommended (30-34), but the ideal time to clamp the cord to promote the most efficient placental transfusion in vaginally delivered (VD) newborns is still undetermined.

Delayed clamping has been associated with a slight increase in the need for phototherapy ( 2.74 vs. $4.36 \%$; $R R<2 \%$ ). This result was much debated, as it originates from the inclusion of unpublished data (McDonald, 1996). No differences between early and delayed clamping were found in mortality rate, Apgar score, admission to NICU, respiratory distress, breastfeeding at discharge and up to 6 months. The incidence of asymptomatic polycythemia was similar between DCC and ICC in the review by McDonald et al. (14) but significantly higher after DCC in the meta-analysis by Hutton et al. (15). Delayed cord clamping has no negative impact on the mother's health compared to immediate clamping (14).
Delayed cord clamping improves iron stores in the first months of life in term, vaginally delivered newborns with a high quality of evidence.

\section{Recommendations}

1. In vaginally delivered newborns, DCC is recommended for at least $60 \mathrm{~s}$ to optimize cardio-pulmonary transition at birth and to promote placental transfusion (strong recommendation) (1A).

2. It is recommended to dry and stimulate non-breathing infants by rubbing the back two to three times to encourage spontaneous breathing before clamping, and to clamp the cord in cases of persistent apnea (strong recommendation) (1B).

3. It is suggested to clamp the umbilical cord by $3 \mathrm{~min}$ after delivery to improve iron stores in the first 3-6 months of life, although the optimal clamping time has not been defined (weak recommendation) (2B).

4. Clamping the umbilical cord at $3 \mathrm{~min}$ is not mandatory; a longer DCC is suggested (up to $5 \mathrm{~min}$, until pulsations stop, etc.) if requested by parents (weak recommendation) (2C).

5. During DCC, newborns may be placed on the mother's abdomen or chest or kept below the perineal plane (weak recommendation) (2C).

\section{Delayed Cord Clamping in Cesarean-Delivered Term Newborns}

A recent meta-analysis (52) showed that cesarean deliveries (CD) at term were associated with a higher amount of cord blood retained by the placenta [mean difference of $8.87 \mathrm{ml}$ (95\% CI 2.32-15.43)] compared to vaginal deliveries. Maternal arterial pressure, the absence of uterine contractions, the possibility of reverse flow from the newborn to the placenta was thought to influence placental transfusion performance (52-54).

Zhou et al. (52) observed that CD newborns had lower hematocrit $(-2.9 \%, \mathrm{CI}-4.16 /-1.65,7$ studies 5,098 newborns), lower hemoglobin concentration $(-0.51 \mathrm{~g} / \mathrm{dl}, \mathrm{CI}-0.74 /-0.27$; 7 studies, 6,563 newborns), and lower red blood cells count $(-0.16 \times 1012, \mathrm{CI}-0.30 /-0.01 ; 3$ studies, 3,858 newborns $)$ compared to VD newborns. The difference in hematocrit was more pronounced in elective $\mathrm{CD}$ than in cesarean section performed in labor; recently, Glasser et al. (55) confirmed these results. The timing of the cord clamping was not specified in the studies included in the meta-analysis.

At present, recommendations on DCC in term newborns do not distinguish between vaginal and cesarean deliveries even though no studies explored the effects of DCC in exclusively $\mathrm{CD}$ newborns and only a few of them included this category of patients (56-58).

Ceriani et al. (56) recruited 266 term newborns to ICC or DCC for 1 or $3 \mathrm{~min}$, respectively; about $30 \%$ of patients in each group were born by $\mathrm{CD}$. The authors demonstrated that DCC augmented hematocrit in the physiologic range at $6 \mathrm{~h}$ of life. Patients in the 3-min DCC group showed a non-significant prevalence of NICU admission compared to other groups (8.7 vs. $5.5 \%$ in the 1 -min DCC and $4.3 \%$ in the ICC group); however, these latter results should be interpreted with cautions, as there was no subgroup analysis for CD newborns. Ertekin 
et al. (57) demonstrated higher serum ferritin concentration at 2 months of age in 150 term newborns randomized to DCC $(90-120 \mathrm{~s})$ or ICC. The significantly higher rate of CD in the DCC group (30 vs. $4 \%, p<0.001$ ) may have affected results but confirmed the effectiveness of DCC on iron stores in CD term newborns. Recently, Andersson et al. (58) compared 64 term infants born by elective CD and recruited to $30 \mathrm{~s}$ DCC to a historical cohort of VD newborns whose cord was clamped by $3 \mathrm{~min}$ after birth (46). The authors found no differences in hematological parameters at 6 months of age between groups suggesting that, in term CD newborns, cord clamping after $30 \mathrm{~s}$ from birth was sufficient to ensure iron status like that achieved by VD newborns after $180 \mathrm{~s}$ DCC. There are no reported side effects of DCC in cesarean-delivered newborns and their mothers.

There are few data supporting DCC longer than $1 \mathrm{~min}$ in cesarean-delivered newborns to improve iron stores in infancy; the higher rate of NICU admission associated to 3 min DCC in the study by Ceriani et al. (56) should be further explored.

No studies compared different positions of the newborn during DCC; infants can be placed between maternal legs or beside the maternal abdomen.

Overall, DCC by 30-60 s in CD term newborns is associated with improved iron stores in the first weeks after birth, with a moderate quality of evidence.

\section{Recommendations}

1. It is suggested to delay cord clamping for at least $30 \mathrm{~s}$ and up to $60 \mathrm{~s}$ after birth to improve iron stores in newborns not requiring resuscitation (weak recommendation) (2B).

2. It is recommended to dry and stimulate non-breathing infants by rubbing the back two to three times to encourage spontaneous breathing before clamping, and to clamp the cord in cases of persistent apnea (strong recommendation) (1B).

3. In the case of DCC longer than $1 \mathrm{~min}$, it is recommended to ensure the presence of a skilled operator in neonatal resuscitation to evaluate the feto-neonatal transition (weak recommendation) $(2 \mathrm{D})$.

\section{Cord Milking in Vaginally and Cesarean-Delivered Term Newborns}

There are only a few studies $(13,59-62)$ that evaluated the effect of UCM in term newborns, most of them including both vaginal and cesarean deliveries, for a total number of about 500 infants receiving UCM, mostly with cut-cord technique. Recently, a pilot trial demonstrated that milking the intact cord provided a greater blood volume compared to the cut-cord technique (63).

Cord milking was associated to improved iron stores in the first weeks of life $(59,60)$, compared to ICC; however, data on the effects of UCM in the first months after birth are scant (61).

Erickson-Owens et al. (59) randomized $24 \mathrm{CD}$ term newborns to ICC or intact-cord UCM. Infants in the intervention group showed a higher hematocrit at $48 \mathrm{~h}$ of life, without differences in the Apgar score and the bilirubin peak.

Upadhyay et al. (60) enrolled two hundred newborns with gestational age $\geq 35$ weeks, to ICC or c-UCM; more than fifty percent (56-66\%) were cesarean-delivered. The prevalence of maternal anemia was around fifty percent in both groups. Milking the cord was associated to higher hemoglobin and blood pressure in the first $48 \mathrm{~h}$ of life and higher hemoglobin [11.9 (1.5) gr/dl vs. 10.8 (0.9) gr/dl, $p<0.05$ ] and ferritin concentrations at 6 weeks of age $[355.9$ (182.6) $\mathrm{mcg} / \mathrm{l}$ vs 177.5 (135.8) $\mathrm{mcg} / \mathrm{L}, p<0.05]$, compared with the control group.

The positive effects of c-UCM on iron stores lasted up to 6 months of age in a prospective study on 200 term newborns (61). The final analysis included 179 newborns; CD rate was between 52 and 59\%. Mean serum ferritin was significantly higher in the intervention group $\left(113.9 \pm 43.8 \mathrm{ng} \mathrm{ml}^{-1}\right.$ vs. $70.8 \pm 39.5 \mathrm{ng} / \mathrm{ml}$, $P<0.001$ ), compared to controls. The efficacy of c-UCM did not vary with the maternal anemia status. In two other studies, DCC (60-90 s) was compared to other placental transfusion strategies $(13,62)$.

The comparison of different placental transfusion strategies in term newborns was inconclusive.

Jaiswal et al. (62) found no significant difference in ferritin and hemoglobin concentrations at 6 weeks of age in a cohort of term newborns (100 patients per arm, $80 \%$ born by CD) randomized to DCC (60-90 s) or c-UCM.

Yadav et al. (13) in a 3-arms randomized trial compared cUCM to DCC and DCC followed by cut-cord UCM (100 patients per arm, gestational age $\geq 37$ weeks, $40 \% \mathrm{CD}$ ). The most efficient technique to improve serum ferritin level at 6 weeks of age was the combined intervention of DCC plus c-UCM, followed by the DCC technique. The authors did not report side effects in the DCC + UCM group.

None of the previous studies provided a separate analysis by type of delivery.

Some authors suggested to milk the uncut cord if this is still full at the end of the time allotment (5) but this option has not been evaluated in clinical trials.

To our knowledge, the uncut UCM technique has not been compared to DCC in VD term newborns. The panel estimated that UCM (both techniques) in healthy vaginally-delivered term newborns should not replace a more physiological placental transfusion obtained by DCC.

Overall, c-UCM improves iron stores in CD term newborns in the first weeks of life, compared to immediate cord clamping, with a very low quality of evidence.

It is not possible to recommend the best milking technique to adopt. The uncut UCM technique may probably result in better transfusion performance but required further evaluation, both in $\mathrm{VD}$ and $\mathrm{CD}$ term newborns.

\section{Recommendations}

\section{Cord milking in vaginally delivered term newborns}

Umbilical cord milking (both techniques) is not suggested as an equal alternative to delayed cord clamping in VD newborns not requiring resuscitation at birth (weak recommendation) (2C).

\section{Cord milking in cesarean-delivered term newborns}

In $\mathrm{CD}$ newborns, if delayed cord clamping is not feasible, umbilical cord milking is suggested as a valid alternative to 
promote placental transfusion and improve iron stores in the first weeks of life. (weak recommendation) (2C).

\section{Delayed Cord Clamping in Late Preterm Newborns}

Delayed cord clamping in late preterm infants $\left(34^{0} / 7-36^{6} / 7\right.$ weeks of gestational age) varied from 30 to $180 \mathrm{~s}$ after birth (64-72).

During DCC, infants were positioned on the mother's abdomen $(64,65)$, below or at the level of the perineal plane (66-72); no comparative studies evaluated the extent of placental transfusion based on different newborn's positions.

Strauss et al. (65) documented a significant increase in the circulating red blood cells volume in VD, but not CD, 30-36 weeks preterm newborns after $60 \mathrm{~s}$ of DCC compared to early clamping ( $42.1 \pm 7.8$ vs. $36.8 \pm 6.3 \mathrm{ml} / \mathrm{kg}, p=0.04)$. Salae et al. (66) randomized 86 VD late-preterm newborns to $120 \mathrm{~s}$ DCC or early clamping, demonstrating improved hemoglobin concentration at $48 \mathrm{~h}$ of life in the DCC group. Similar results were obtained by Ultee et al. (64) in a randomized trial on 37 VD late preterm newborns (18 in DCC group and 19 in the ICC group), where $180 \mathrm{~s}$ DCC was associated to higher hemoglobin concentration at 10 weeks of life.

Ranjit et al. (67) randomized 100 preterm newborns (30-36+6 weeks, of gestational age, mean gestational age 34 weeks, $47 \%$ CD) to ICC or $120 \mathrm{~s}$ DCC. The latter cohort showed higher mean hematocrit $(27.3 \pm 3.8$ vs. $31.8 \pm 3.5 \%, p<0.00)$ and mean serum ferritin $(136.9 \pm 83.8$ vs. $178.9 \pm 92.8 \mathrm{ng} / \mathrm{ml}, p=0.037)$ at 6 weeks of age compared to ICC. Other studies that included late preterm newborns confirmed that clamping the cord 30-60 s after birth increased blood pressure in the first $24 \mathrm{~h}$ after birth and hemoglobin/hematocrit values at different time points, up to 10 weeks of age if their cord were clamped after 30-60 s from birth $(60,69-72)$. In the trial by Ashish et al. (48) term and late preterm vaginally delivered newborns [mean GA(SD): 39.2 (1.1) weeks] were randomized to ICC or $180 \mathrm{~s}$ DCC. The incidence of iron deficient anemia was significantly lower in the DCC group; however, the number of late preterm infants was not provided by the authors.

Most of the studies included late preterm newborns, but only a few of them addressed to this specific category, with a very low number of patients recruited $(64,66,72)$. The available data do not allow to differentiate the effect of DCC by mode of delivery. Overall, the quality of evidence was considered low or very low for the outcomes considered (iron store and hemoglobin concentration in the first weeks of life).

\section{Recommendations}

1. In vaginal and cesarean-delivered infants not breathing at birth, it is recommended to dry and stimulate by rubbing the back two to three times to encourage spontaneous breathing before clamping, and to clamp the cord if the baby continues not to breath (strong recommendation) (1B).

2. It is recommended the presence of personnel with neonatal resuscitation skills to evaluate the newborn in the transition phase (strong recommendation) (1B).

\section{DCC in vaginally delivered late preterm newborns}

1. It is suggested clamping the cord between 60 and $180 \mathrm{~s}$ in vaginally delivered newborns, not requiring resuscitation at birth, to improve hemoglobin concentration and iron stores in the first weeks after birth (weak recommendation) (2C).

2. It is suggested placing newborns from vaginal delivery at the perineal level or below for the first $30 \mathrm{~s}$ of DCC, then on maternal abdomen (weak recommendation).

\section{DCC in cesarean-delivered late preterm newborns}

1. It is suggested clamping the cord between 30 and $60 \mathrm{~s}$ in cesarean-delivered late preterm newborns not requiring resuscitation (weak recommendation).

\section{Cord Milking in Late Preterm Newborns}

Only one study that included late preterm infants evaluated the effects of UCM (73), with the cut-cord technique.

Kumar et al. (73) demonstrated in a randomized trial (32$36+6$ weeks of GA, mean 34.5 weeks, 100 patients per arm, 61 and 56\% CD newborns in the ICC group and DCC group, respectively) that $\mathrm{c}-\mathrm{UCM}$ improved hemoglobin and ferritin concentration at 6 weeks of life, compared to early clamping. No studies compared UCM with DCC in selected populations of exclusively late preterm newborns.

No data are available on the extent of placental transfusion with milking techniques, differentiated by mode of delivery.

Umbilical cord milking improves iron stores in the first weeks after birth in late preterm infants, with a very low quality of evidence.

Delayed cord clamping and milking were not associated with adverse events both in newborns and in the mother.

\section{Recommendations}

In vaginally and cesarean-delivered late preterm newborns, when DCC is not feasible, UCM is suggested as a valid alternative to improve iron stores (weak recommendation).

\section{Placental Transfusion in Newborns Less Than 34 Weeks of Gestational Age Delayed Cord Clamping}

Delayed cord clamping in very preterm infants is defined as a clamping that occurs between 30 and $120 \mathrm{~s}$ after birth; DCC longer than $120 \mathrm{~s}$ has not been tested.

The most recent results on the effect of DCC in preterm infants were published in 2017.

The Australian APTS trial (24) that enrolled 1,566 newborns with GA $<30$ weeks failed to demonstrate any benefits deriving from delayed clamping for $60 \mathrm{~s}$ or more when compared to immediate cord clamping. Specifically, the authors found no difference in the incidence of severe IVH, hospital mortality, severe brain injury, late-onset sepsis, retinopathy of the prematurity, necrotizing enterocolitis, and chronic lung disease between early and delayed clamping groups.

This study did not foresee interventions to promote breathing during DCC and may explain the high protocol violation rate (about $1 / 4$ of subjects randomized to DCC received ICC) mostly due to medical concern about the infant. The exclusion of the 
most critical newborns may have affected the results. Indeed, statistical analysis has not been performed on the effective treatment received by the patient but based on the treatment expected by randomization, which may have introduced an attrition bias, caused by the unequal loss of patients in the DCC group.

The second significative study was the meta-analysis by Fogarty et al. (25) that included 2,834 preterm infants (996 infants $\leq 28$ weeks gestation) from 18 randomized trials (including the APTS trial) of delayed vs. early cord clamping. This study provided high quality evidence that DCC (mostly $\geq 60 \mathrm{~s}$ ) reduced hospital mortality by $30 \%$, in newborn $\leq 28$ weeks GA (RR $0.70,95 \% \mathrm{CI}-0.09$ to -0.01 , number needed to benefit 20), compared to ICC and reduced the proportion of infants having blood transfusion by 10\% (95\% CI 6 to $13 \%, P<0.00001)$. Subgroup analyses showed no differences between randomized groups in Apgar scores, intubation for resuscitation, admission temperature, mechanical ventilation, intraventricular hemorrhage, brain injury, chronic lung disease, patent ductus arteriosus, necrotizing enterocolitis, late-onset sepsis, and retinopathy of prematurity.

The authors explained the positive impact of DCC in preterm newborns with the reduction of unnecessary and potentially harmful medical interventions in the first hours and days of life that could influence short and long-term outcomes through the activation of the inflammatory cascade and oxidative stress, the increased risk of infections and lengthening of hospitalization.

Many authors observed that cord clamping should be individualized and based on clinical conditions, rather than on a pre-defined ideal clamping time (7-9).

Ventilation is the key strategy of neonatal resuscitation (74) but most very and extremely preterm infants start breathing, spontaneously or after stimulation, before $1 \mathrm{~min}$ after birth and could safely "wait" before clamping the cord (39-41). In the case of apneic newborns, promoting spontaneous breathing through gentle stimulation during the first 30-60 s of delayed clamping may improve feto-neonatal transition.

Indeed, first steps of stabilization at birth have been associated with reduced peripartum mortality and mask ventilation $(75,76)$; in breathing term and late preterm newborns, every $10 \mathrm{~s}$ of DCC was associated with a $20 \%$ reduction in the risk of death or hospitalization (40).

According to these concepts, the working group proposed a flow chart (Figure 1) for premature deliveries that foresees the presence of the neonatologist at mother's bedside to safely provide at least $30 \mathrm{~s}$ of DCC to all newborns, while ensuring the first steps of stabilization. This model does not, therefore, create significant contradictions between neonatal resuscitation guidelines $(31,32,42)$ and placental transfusion maneuvers and does not require specific equipment. A professional figure (timekeeper) responsible for checking and communicating the time elapsed from birth is suggested by various authors (5).

Delayed cord clamping increased the incidence of polycythemia in preterm newborns [risk difference 3\% (95\% CI: 2 to $5 \%$ )], and the incidence of jaundice (mean difference in peak bilirubin $+4 \mu \mathrm{mol} / \mathrm{l}$ ) without increasing morbidity or the need for exchange transfusion (25).
Preliminary results of long-term follow-up showed a positive correlation between DCC and improved motor function at 18-22 months of corrected age, compared to ICC (77).

Delayed cord clamping, compared to ICC, in moderate, very and extremely preterm deliveries improved outcomes with a high level of evidence.

\section{Umbilical Cord Milking and Resuscitation}

Milking the umbilical cord in very and extremely premature newborns was associated with a significant decreased risk of intracranial hemorrhage of all grade IVH all grade (RR 0.62; CI $0.41-0.93$ ) and bronchopulmonary dysplasia (RR, 0.42 [95\%CI: $0.21-0.83])$ in newborns with gestational age $<33$ weeks, compared to ICC (11) and to reduced red blood cell transfusion in newborns of $<29$ weeks of gestational age (21).

When UCM was compared to DCC, results are contradictory. Rabe et al. (78) did not find differences between UCM and $30 \mathrm{~s}$ DCC in a small cohort of newborns $<33$ weeks of gestational age. The larger randomized study by Katheria et al. (35) that enrolled 197 preterm newborns (mean gestational age $28 \pm 2$ weeks, mostly cesarean-delivered) demonstrated that milking the uncut cord was associated to higher hemoglobin, blood pressure, urine output in the first 12-24 h of life compared to 45-60 s DCC.

The follow-up study of the cohort by Rabe et al. (79) showed no neurodevelopmental differences between DCC and UCM groups at 2 and $31 / 2$-years follow-up while infants randomized to UCM in the study by Katheria et al. (27) had higher language and cognitive scores compared with those randomized to DCC.

In moderate, very and extreme preterm newborns, especially if cesarean-delivered, cord milking improved short-term outcomes with a moderate level of evidence, and long-term outcomes with very low quality of evidence, without undesirable effects, except for a low risk of symptomatic hyperviscosity (80). For these reasons, the working group unanimously considered uncut UCM a valid option to favor placental transfusion when DCC is not feasible.

\section{Recommendations (See Figure 1)}

1. In vaginal and cesarean-delivered newborns with gestational age $<34$ weeks, it is recommended to delay cord clamping for at least 30". During this period, it is recommended to ensure the maintenance of body temperature, to perform tactile stimulation, to ensure airway patency and possibly their aspiration (strong recommendation) (1A). First steps of stabilization at the mother's bedside should be provided by the attending neonatologist (strong recommendation) (1A).

2. At $30 \mathrm{~s}$ of life, it is recommended to evaluate tone and breathing activity by visual inspection and heart rate by stethoscope: if the newborn is bradycardic (heart rate is $<100$ bpm) apnoeic or gasping, it is recommended to clamp the cord and start ventilatory assistance maneuvers according to neonatal resuscitation procedures (strong recommendation) (1A).

3. At $30 \mathrm{~s}$ of life, if the heart rate is $>100 \mathrm{bpm}$ and active breathing or efforts to breath are present, it is recommended to clamp the cord at $60 \mathrm{~s}$ (strong recommendation) (1A). 


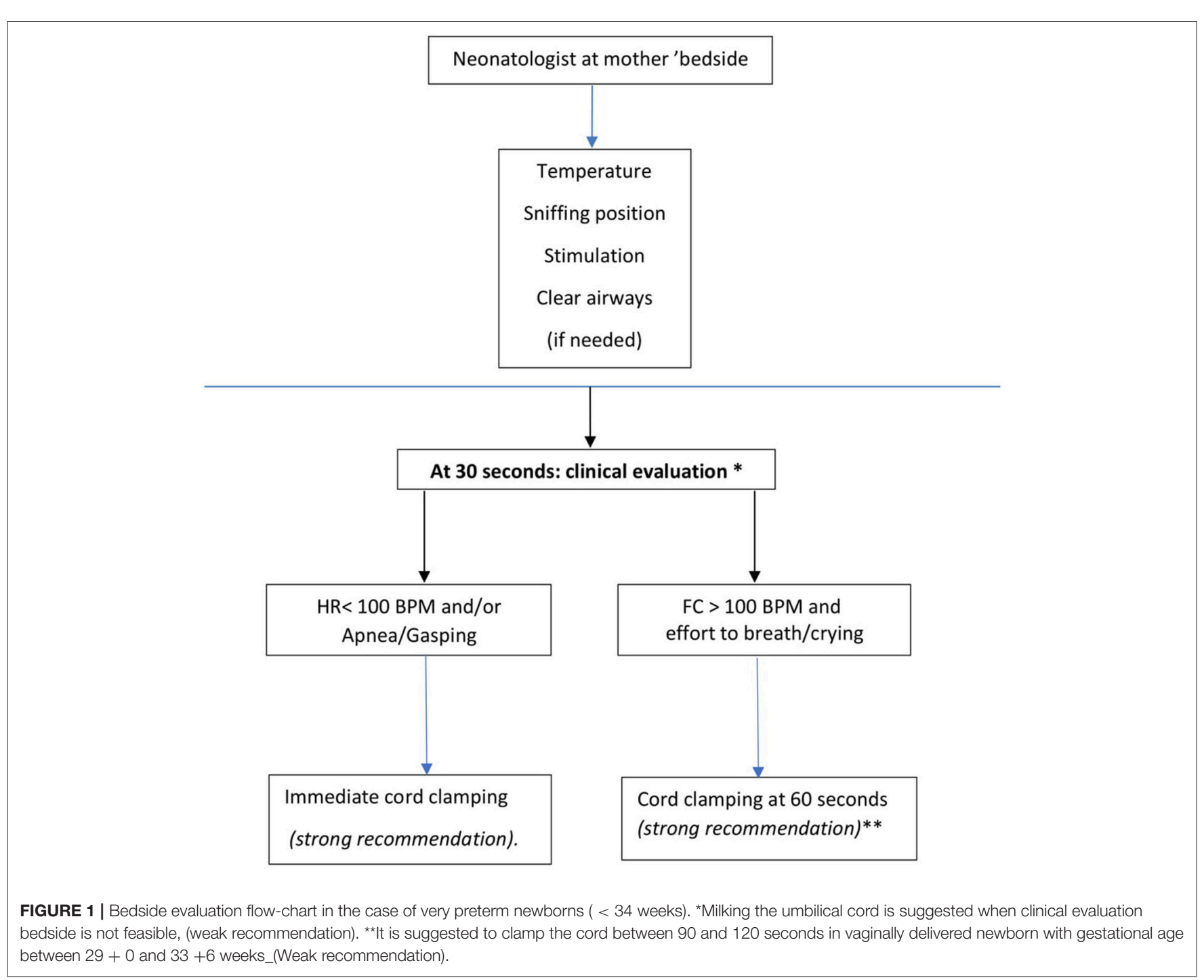

4. In vaginally delivered newborns with gestational age between $29+0$ and $33+6$ weeks, that do not require ventilatory assistance, the umbilical cord may be clamped at $90-120 \mathrm{~s}$ of life (weak recommendation) (2C).

5. The obstetrical-neonatological team should ensure sterility during bedside maneuvers, especially in the operating room (strong recommendation) (1A).

6. It is suggested to place vaginally delivered newborns at or below the perineal plane to promote placental transfusion (weak recommendation) (2C).

7. It is recommended to identify within the obstetricneonatology team a professional figure responsible for checking and communicating the time elapsed from birth (strong recommendation) (1B).

8. When bed-side neonatological assistance could not be implemented, milking the uncut umbilical cord three to four times before clamping the cord is suggested (weak recommendation) (2B).

\section{Pregnancy With Feto-Maternal Red Blood Cell Alloimmunization}

Rhesus disease and, generally, feto-maternal red blood cell alloimmunization, were excluded from DCC research protocols, as it was likely that delaying clamping may increase the risk for significant hyperbilirubinemia due to the higher amount of opsonized red blood cells (RBC) transfused from the placenta to the newborn that could undergo hemolysis.

There is a single retrospective study (81) that compared the effects of $30 \mathrm{~s}$ DCC in a group of neonates with fetal Rh-disease and fetal anemia treated with intra-uterine transfusion to a historical cohort of patients. The authors observed that neonates in the DCC group had higher hemoglobin concentration at birth (13.4 vs. $10.2 \mathrm{~g} / \mathrm{dl} ; p=0.0003$ ), lower incidence of anemia $(\mathrm{Hb}>12 \mathrm{~g} / \mathrm{dl}: 70.6 \%$ vs. $25 \%, p=0.004)$, reduced need for exchange transfusion without increasing the rate of pathologic hyperbilirubinemia. However, the results were not conclusive due to the differences in gestational age (GA), birth weight, mode 
of delivery and management of jaundice between the two study periods.

\section{Recommendations}

1. In newborns at risk of anemia due to feto-maternal alloimmunization, it is suggested clamping the cord within $30 \mathrm{~s}$ from birth, after the first breaths if these occur before $30 \mathrm{~s}$ from birth (weak recommendation).

\section{Delayed Cord Clamping in HIV-Positive Pregnancy}

Antiretroviral therapy during pregnancy together with intrapartum and postnatal prophylaxis can prevent perinatal transmission of HIV-infection from the mother to the newborn $(30,82,83)$.

WHO guidelines (30) suggest delaying cord clamping in HIV women to improve maternal and infant health and nutrition outcomes because benefits outweigh "the theoretical, and unproven, harm" of virus transmission. Newborns exposed to antiretroviral therapy during pregnancy have a higher incidence of neonatal anemia (82); DCC could be effective in increasing hemoglobin concentration in the first weeks of life and reducing the need for iron prophylaxis in infancy. To our knowledge, only one study (84) compared the effect of $2 \mathrm{~min}$ DCC to immediate cord clamping on 64 paired mother-newborn peers. All mothers had a negative viral load $(<1,000$ copies $/ \mathrm{ml})$ and received antiretroviral therapy during pregnancy; all newborns were born by scheduled cesarean delivery. Infants randomized to DCC had significantly higher mean hemoglobin concentration $(17.36 \mathrm{~g} / \mathrm{dl}$, range $13.1-21.1$ $\mathrm{g} / \mathrm{dl}$ ) compared to ICC group $(15.1 \mathrm{~g} / \mathrm{dl}$, range $10.9-21.2 \mathrm{~g} / \mathrm{dl}$ ) and this difference persisted during the first month of life, despite iron supplementation in those with anemia. At 1 year, hemoglobin concentration was similar between the two groups and all newborns showed negative HIV-PCR up to 18 months of life.

Vaginal delivery is considered appropriate for HIV-infected pregnant women who have been maintained on combined antiretroviral therapy and who have viral loads $<1,000$ copies $/ \mathrm{ml}$ at or near delivery (85). Based on this recommendation, in term or near-term newborns from HIV-mother on antiretroviral therapy and viral load of 1,000 copies/ml or less, DCC could theoretically be feasible but, based on the principle of prudence, in the absence of clinical studies, it cannot be recommended. The risk of mother-to-child transmission in HIV-infected women with high viral loads can be reduced by performing cesarean delivery before the onset of labor and before rupture of membranes, in conjunction with peripartum maternal antiretroviral therapy. In these cases, DCC may theoretically increase the risk of vertical transmission. No studies have been conducted on women with high viral load nor in those that have not received antiretroviral therapies during pregnancy.

The following recommendations are intended for HIV pregnancies in high-income countries with scheduled cesarean delivery.

\section{Recommendations}

1. In newborns from HIV-positive mothers with adequate antiretroviral therapy during pregnancy and HIV-RNA near or at delivery $\leq 1,000$ copies $/ \mathrm{ml}$ it is suggested to delay cord clamping for at least $30 \mathrm{~s}$ and up to $60 \mathrm{~s}$ to improve iron stores, similarly to what suggested for healthy term and late preterm $\mathrm{CD}$ newborns (weak recommendation) (2C).

2. Immediate cord clamping is suggested in all other cases (weak recommendation) (2C).

\section{Placental Transfusion Strategies and Twin Pregnancies}

Various studies (86-88) showed that the second VD newborn twin had significantly higher hemoglobin concentration at birth and in the first days of life, compared to the first one, both in monochorionic and dichorionic pregnancies.

The higher hemoglobin concentration in the secondborn from monochorionic twin has been addressed to the presence of vascular anastomoses allowing either intrapartum inter-twin blood transfusion or placenta-fetal transfusion (86); in dichorionic twins the difference in hemoglobin concentration could be related to a different time of cord clamping between the first and second vaginally delivered newborn (87).

Lopriore et al. (86) retrospectively analyzed hemoglobin concentrations at birth and after 2 days of life in 300 dichorionic and 290 monochorionic preterm twin pairs. In both dichorionic and monochorionic VD twins, second-born showed a higher hemoglobin level at birth compared with their co-twin.

In twins delivered through cesarean section, no intertwin differences in hemoglobin levels were detected.

Very few studies on placental transfusion strategies included dichorionic twin pregnancies, and none included monochorionic twins.

Mc Donnel et al. (89) evaluated 46 infants (26-33 weeks of gestational age, mostly $\mathrm{CD}$ ) randomly assigned to $30 \mathrm{~s}$ DCC or early clamping. Four sets of twins were included; a twin-to-twin transfusion occurred in one case of monochorionic/diamniotic pregnancy and, in another case, the first newborn showed marked anemia due to feto-maternal hemorrhage. The authors found no difference between groups in mean hematocrit in the first hours of life.

Kugelman et al. (68) randomized 65 newborns (mean gestational age 32 weeks, $65 \%$ CD) to $30-45$ s DCC or ICC. The number of neonates born from multiple pregnancies (seven twin and one triplet pregnancies) was similar in the two groups. There was no significant difference in initial hematocrit between the first and the second newborn. DCC in multiple pregnancies was not associated with anemia or polycythemia (mean hematocrit: $53.2 \%$; range vs. $54.2 \% ; p<0.74$ ). In one twin pregnancy and the triplet one, the hemoglobin difference was $<5 \mathrm{~g} / \mathrm{dl}$.

In the recent study by Katheria et al. (41), premature infants $(23+0-31+6 / 7$ weeks' gestational age $)$ were randomized to receive positive pressure ventilation during DCC, or DCC and stimulation. The total number of newborns enrolled was 150, 125 of whom were born by $\mathrm{CD}$. Multiple pregnancies were included, 
but there was no subgroup analysis for this category of patients; however, no adverse events were recorded.

The APTS trial (24) included two hundred-ninety newborns (about $25 \%$ of the cohort) born from twin pregnancies, including triplets and quadruplet. As for previous research studies, data on outcomes for this category of patients lack but no side effects were reported, both from vaginal or cesarean-delivered newborns.

The quality of evidence has been considered low or very low, due to the paucity of data on this subset of patients; however, the panel considered delayed cord clamping in twin pregnancies safe for mother and the child.

No studies evaluated the effect of milking in this group of patients.

\section{Recommendations}

1. Delayed cord clamping is not recommended in monochorionic twins because the risk of acute intertwin transfusion at birth outweighs the undetermined benefit of delayed cord clamping in this population. (strong recommendation) (1B).

2. In vaginally and cesarean-delivered term or preterm twin newborns from dichorionic pregnancy, it is suggested delaying cord clamping for at least $30 \mathrm{~s}$ up to $60 \mathrm{~s}$ (weak recommendation) (2D).

3. In vaginally and cesarean-delivered infants not breathing at birth, it is recommended to dry and stimulate by rubbing the back two to three times to encourage spontaneous breathing before clamping, and to clamp the cord if the baby continues not to breath (strong recommendation) (1B).

\section{Congenital Heart Diseases (CHD)}

The hemodynamic and hematological improvements associated with DCC could theoretically advantage newborns with CHD. Indeed, the increased blood volume and hematocrit may have a positive effect, especially in cyanotic CHD, through the improvement of tissue oxygenation and increased blood flow at the level of Foramen Ovale and Ductus Arteriosus.

There is a single randomized study (90) that evaluated DCC (up to $120 \mathrm{~s}$ ) in a population of 30 newborns with severe CHD requiring corrective intervention within 1 month of life. Most of them were born by vaginal delivery; the mean clamping time was $114 \mathrm{~s}$. There was no difference in perinatal events between groups. Newborns randomized to DCC significantly increased their hematocrit in the first $72 \mathrm{~h}$ and reduced red blood transfusion requirement both before and after surgical correction, while the incidence of thrombotic events did not increase. The authors concluded that DCC was a safe and feasible procedure for newborns with severe CHD.

Based on the prediction of hemodynamic conditions at birth (91), CHD could be categorized into three groups:

1) $\mathrm{CHD}$ without prediction of hemodynamic instability at birth: interatrial and interventricular septal defects, mild to moderate degree of valvular abnormalities.

2) CHD with a slight risk of hemodynamic instability at birth: obstructions to the right or left efflux with arterial duct dependence. In these conditions, the patency of the arterial duct in the first hours after birth generally allows a physiologic cardiorespiratory and hemodynamic transition at birth.

3) CHD with a high probability of hemodynamic instability at birth could compromise postnatal transition and required immediate resuscitation:

- Transposition of great vessels with a restrictive foramen ovale

- Hypoplastic left heart syndrome with a restrictive foramen ovale

- Total abnormal pulmonary venous return obstructed

- Ebstein disease with hydrops

- Tetralogy of Fallot with absent pulmonary valve

- Heart rhythm disorders with decompensation.

\section{Recommendations}

1. DCC between 1 and $2 \mathrm{~min}$ is suggested in the case of vaginally delivered CHD newborns (weak recommendation) (2C).

2. It is suggested clamping the cord at $1 \mathrm{~min}$ in the case of cesarean-delivered CHD newborns (weak recommendation) (2D).

3. In the case of mild or severe risk of hemodynamic instability, (group 2 and 3), it is recommended to foresee the presence of personnel with resuscitation skills to evaluate the newborn during the transition phase (strong recommendation) (1B).

4. The management of cord clamping in the case of severe CHD (group 3) should be discussed prenatally by a multidisciplinary team (obstetrician, neonatologist, and cardiologist) according to the predictable resuscitation needs. (weak recommendation) (2C).

\section{Blood Gas Analysis and Delayed Cord Clamping}

Blood gas analysis from the umbilical artery is a tool to assess the metabolic status of the fetus (92). It provides quality control of obstetric care and has medicolegal implications (93). The recommended technique is to collect the blood sample from a double-clamped segment of the umbilical cord immediately after delivery of the newborn (94).

Scientific Societies (95-97) recommend performing venous and arterial cord blood gas analysis in the following situations: fever in labor; meconium-stained amniotic fluid; abnormal CTG tracing; cesarean section performed for fetal compromise; uncompensated maternal thyroid diseases; operative delivery; shoulder dystocia and twin delivery. Most of these cases, where fetal distress is suspected, and blood gas analysis recommended within a few seconds from birth, are associated with an adequate post-natal cardio-respiratory adaptation, and DCC could be safely performed. Various studies, however, demonstrated that cord acid-base status significantly worsens with time.

Wiberg et al. (98) evaluate cord blood gas analysis in 70 vaginally delivered term newborns, sampled at birth and every $45 \mathrm{~s}$ until cord pulsations stopped. They found a significant, time-dependent decrease of arterial $\mathrm{pH}$, bicarbonates, and $\mathrm{BE}$, and a significant increase of $\mathrm{PaCO} 2$, PO2 and lactate from T0s to T90s, with the most pronounced 
changes between T0s andT45s. Valero et al. obtained similar results (99).

De Paco et al. (100) found no significant differences in acidbase status evaluated in paired cord blood samples obtained immediately after birth or after to 2-min DCC in a cohort of term newborns. This methodological difference, compared to other studies, together with the small sample size, may explain the observed discrepancies.

All these studies included infants who did not require resuscitation at birth; whether the effect of DCC on arterial cord $\mathrm{pH}$ in non-vigorous infants would be similar is an important question requiring further investigations.

A possible solution that takes both needs into account (blood gas determination immediately after birth and delayed cord clamping in vigorous infants) is to perform blood gas analysis on the unclamped umbilical cord. Andersson et al. (93) showed that this technique is a feasible alternative method for obtaining umbilical blood samples within $30 \mathrm{~s}$ from birth without reducing the proportion of valid blood gas samples and without significant differences in blood gas parameters compared to the doubleclamped technique.

Di Tommaso et al. (101) demonstrated that, in neonates from uncomplicated pregnancy and labor, blood gas analysis obtained from unclamped cords immediately after birth provides reliable indications on the state of fetal oxygenation without altering the accuracy of the analysis, when compared to the clamped technique, especially on the arterial side.

The quality of evidence was considered high for the outcome "reliability of cord blood gas analysis during delayed cord clamping."

\section{Recommendation}

1. It is recommended performing umbilical artery gas analysis on double-clamped cord immediately after birth when neonatal asphyxia is expected, to obtain the most objective determination of the neonatal metabolic condition at of birth (strong recommendation) (1A).

2. When cord gas analysis is recommended immediately after birth, but the newborn is vigorous and does not require resuscitation, umbilical artery gas analysis on the unclamped cord is a feasible alternative method (strong recommendation) (1B).

\section{Cord Blood Banking and Delayed Cord Clamping}

Umbilical Cord Blood (UCB) is currently an established source of stem cells, especially in pediatric settings, in very urgent cases and for patients with no HLA matched donor $(102,103)$.

In recent years, the cellularity threshold for banking has been augmented from $1.2 \times 10^{9}$ to $1.5 \times 10^{9}$; consequently, discarded units are increased up to over $75 \%$ (104).

Numerous factors may condition the collection of adequate UCB units; 1. weight of the newborn, 2. weight of the placenta, 3 . ethnicity, and 4. collection methods (in-utero vs. ex-utero). The timing of cord clamping is the main determinant of volume and number of stem cells collected (105-107).
Early cord clamping within $30 \mathrm{~s}$ from delivery is associated with optimal volume and progenitor cells for UCB collection while DCC for 1 to 3 min significantly reduces cord blood volume available for collection $(108,109)$.

A study from the Canadian Blood Bank Service (108) showed that any cord clamping delay from birth to collection decreased the number of UCB units that met the threshold for banking; clamping the cord after $120 \mathrm{~s}$ correlated with the highest number of discarded cord blood units.

Differently, the National Swedish Cord Blood Bank (109) demonstrated that, although $60 \mathrm{~s}$ DCC was associated with a reduced volume of blood (mean difference, $8.1 \mathrm{ml}$; 95\% CI, 1.3$15.0 \mathrm{ml}$ ), it did not impact negatively on the total number of stem cells collected ( $p=0.1$ ) (in-utero technique, threshold 1.5 $\times 10^{9}$ ).

Recent recommendations (110-113) stated that UCB collection must not adversely affect mother' or newborn 'health and cord blood collection should not interfere with DCC. Since 2011, an Italian state-region agreement stated that the cord should not be clamped before $60 \mathrm{~s}$, in the case of public cord blood donation.

Scientific societies (109-112) recommend providing pregnant women with unbiased information about umbilical cord blood banking options, including the benefits and limitations of public and private banks.

The following recommendations are intended for altruistic and dedicated umbilical cord blood (UCB) donations. Private cord blood banks are not allowed in Italy. Cord blood may be collected with special permission from the hospital, but units must be stored in foreign cord blood banks; transport and costs are not borne by national health service.

\section{Recommendations}

1. In the case of altruistic cord blood donation, it is suggested to clamp the umbilical cord after $60 \mathrm{~s}$ and before $120 \mathrm{~s}$ after birth (weak recommendation) (2C).

2. In the case of directed donation for at-risk families, with the goal of maximizing the content of hematopoietic progenitors through the volume collected, it is recommended to clamp the cord immediately after birth (strong recommendation) (1A).

3. Health care professionals should give written information to pregnant women and their partners of the benefits of DCC and its impact on cord blood collection and banking (strong recommendation) (1B).

\section{CONTRA-INDICATIONS TO DELAYED CORD CLAMPING AND UMBILICAL CORD MILKING}

Although there are no maternal contraindications to DCC or UCM, there are some emergent conditions (such as massive uterine bleeding) that required immediate cord clamping to safeguard mother's health.

Fetal conditions for which DCC and UCM are contraindicated include all cases of perinatal asphyxia when immediate resuscitation is required; other exclusion criteria 
include clinical situations for which concerns exist about the possible benefits deriving from a placental transfusion, and results from research studies, when present, are inconclusive.

For the following clinical situations, immediate cord clamping is recommended, although based on experts' opinions.

- Birth asphyxia secondary to hypoxic-ischemic events: placental detachment, cord prolapse, uterine rupture, shoulder dystocia, vasa previa rupture, maternal collapse, amniotic embolism, maternal cardiac arrest.

- Twin to twin transfusion (TTTS)

- Newborn from HIV-positive mother (see dedicated paragraph)

- Fetal hydrops with evidence of fetal hearth decompensation

- Doubt about the integrity of the umbilical cord

- Cesarean delivery under general anesthesia.
Theoretically, when a hypovolemic shock is suspected (i.e., shoulder dystocia, placental detachment, cord prolapse, uterine rupture) c-UCM may be an immediate source of fetal blood to be transfused while initiating resuscitations 'maneuvers (113). Research protocols are required to evaluate this option.

\section{Intra-uterine Growth Restriction (IUGR)}

Intrauterine growth restriction refers to a fetus with an estimated fetal weight $<10$ th percentile on ultrasound that, because of a pathologic process, has not attained its growth potential (114). The leading cause of IUGR is uteroplacental insufficiency (115), but fetal restriction could also be associated with maternal or fetal factors. In most cases, the fetus is exposed to chronic hypoxia that leads to polycythemia due to the increased erythropoietin secretion during fetal life (116). Increased hematocrit and blood viscosity could augment the risk

TABLE 2 | Summary of recommendations.

Newborns $\geq 34$ weeks GA

Vaginally delivered

Cesarean-delivered

Newborns < 34 weeks GA

HIV pregnancy

Twin pregnancy

Fetus with congenital heart disease (CHD)

Cord blood banking

Blood gas analysis

Contra-indications to DCC and UCM
- Always dry and stimulate apnoeic infants before clamping, to encourage spontaneous breathing, and to clamp the cord in cases of persistent apnea

- In term and late preterm newborns, delay cord clamping for at least 30 (late preterm) or 60 s (term) and up to 3 min to optimize cardiopulmonary transition and improve iron stores

- Consider the mother's choice if she asks for a longer DCC

- Place the newborn on the mother's abdomen/chest or kept below the perineal plane

- Delay cord clamping for at least 30 (late preterm) or 60 (term) s

- In the case of DCC longer than 60 s ensure the presence of a skilled operator in neonatal resuscitation to evaluate the feto-neonatal transition

- Milking the umbilical cord in term and late preterm newborns is a valid option when DCC is not feasible

- Ensure the neonatologist is at the bedside

- After newborn'delivery, maintain body temperature and airway patency, stimulate, and aspirate airways when required

- Evaluate breathing and cardiac frequency at $30 \mathrm{~s}$ : 1. Clamp the cord and resuscitate if apnoeic or bradycardic (< $100 \mathrm{bpm})$.

2. If heart rate $>100 \mathrm{bpm}$ and active breathing/efforts to breath: CD newborns or GA < 29 weeks: clamp the cord at $60 \mathrm{~s}$. VD newborns with GA 29-33 weeks: clamp the cord at 90-120 s.

- Milking the cord is a valid alternative when a newborn's evaluation at mother's bedside is not feasible

- Ensure sterility during bedside maneuvers

- Clamp the cord between 1 and 2 min in CD newborns from HIV-positive mothers with HIV-RNA $\leq 1,000$ copies/mL and adequate antiretroviral therapy during pregnancy

- Immediate cord clamping in other cases

- In monochorionic twin, delayed cord clamping is not recommended

- In vaginally and cesarean-delivered term or preterm twin newborns from dichorionic pregnancy, it is suggested delaying cord clamping for at least $30 \mathrm{~s}$ up to $60 \mathrm{~s}$

- DCC between 1 and 2 min is suggested in VD newborns

- DCC for 1 min is suggested in the case of CD

- In the case of $\mathrm{CHD}$ at high-risk of hemodynamic instability, discuss antenatally the management of cord clamping

- In the case of altruistic cord blood donation, it is recommended clamping the cord after $60 \mathrm{~s}$ and before $120 \mathrm{~s}$

- In the case of dedicated cord blood donation, it is recommended clamping the cord immediately after birth.

- Offer written information to pregnant women and their partners of the benefits of DCC and its impact on cord blood collection and banking

- Perform umbilical artery gas analysis on double-clamped cord immediately after birth when neonatal asphyxia is expected - When cord gas analysis is recommended immediately after birth, but the newborn is vigorous and do not require resuscitation, umbilical artery gas analysis on the unclamped cord is a feasible alternative method

- Birth asphyxia secondary to hypoxic-ischemic events: placental detachment, cord prolapse, uterine rupture, shoulder dystocia, vasa previa rupture, maternal collapse, amniotic embolism, maternal cardiac arrest

- Twin to twin transfusion (TTSS)

- HIV positive mother (see dedicated paragraph)

- Rhesus disease

- Fetal hydrops

- Doubts about the integrity of the umbilical cord

- Cesarean delivery under general anesthesia 
of neonatal morbidities, like respiratory distress, thrombosis, and cerebrovascular accidents (116).

Delayed cord clamping and cord milking have not been tested in this specific population; for this reason, the panel could not issue a recommendation on the subject. Theoretically, both techniques may worsen polycythemia $(25,81)$ and hyperviscosity, augmenting the risk of neonatal events, especially in infants with severe fetal restriction. The management of cord clamping in these cases should be discussed antenatally with the obstetric team.

\section{SUMMARY OF RECOMMENDATIONS}

A summary of all recommendations is given in Table 2.

\section{AUTHOR CONTRIBUTIONS}

SG conceived the project, coordinated the work of the panel between 2015 and 2016, wrote the introduction and the material and methods paragraphs, wrote and reviewed

\section{REFERENCES}

1. Raju TN, Singhal N. Optimal time for clamping the umbilical cord after birth. Clin Perinatol. (2012) 39:889-900. doi: 10.1016/j.clp.2012.09.006

2. Raju TN. Timing of umbilical cord clamping after birth for optimizing placental transfusion. Curr Opin Pediatr. (2013) 25:180-7. doi: 10.1097/MOP.0b013e32835d2a9e

3. Mercer JS. Current best evidence: a review of the literature on umbilical cord clamping. J Midwifer Womens Health (2001) 46:402-14. doi: 10.1016/S1526-9523(01)00196-9

4. Carroll PD, Christensen RD. New and underutilized uses of umbilical cord blood in neonatal care. Matern Health Neonatol Perinatol. (2015) 1:16. doi: 10.1186/s40748-015-0017-2

5. Katheria AC, Lakshminrusimha S, Rabe H, McAdams R, Mercer JS. Placental transfusion: a review. J Perinatol. (2016) 37:105-11. doi: 10.1038/jp.2016.151

6. Yao AC, Moinian M, Lind J. Distribution of blood between infant and placenta after birth. Lancet (1969) 25:871-3. doi: 10.1016/S0140-6736(69)92328-9

7. Katheria A, Rich W, Finer N. Optimizing care of the preterm infant starting in the delivery room. Am J Perinatol. (2016) 33:297-304. doi: $10.1055 / \mathrm{s}-0035-1570385$

8. Niemeyer S, Velaphi S. Promoting physiologic transition at birth: reexamining resuscitation and the timing of cord clamping. Semin Fetal Neonatal Med. (2013) 18:385-92. doi: 10.1016/j.siny.2013.08.008

9. Kluckow M, Hooper SB. Using physiology to guide time to cord clamping. Semin Fetal Neonatal Med. (2015) 20:225-31. doi: 10.1016/j.siny.2015. 03.002

10. Hooper SB, te Pas AB, Lang J, van Vonderen JJ, Roehr CC, Kluckow M, et al. Cardiovascular transition at birth: a physiological sequence. Pediatr Res. (2015) 77:608-14. doi: 10.1038/pr.2015.21

11. Al-Wassia H, Shah PS. Efficacy and safety of umbilical cord milking at birth: a systematic review and meta-analysis. JAMA Pediatr. (2015) 169:18-25. doi: 10.1001/jamapediatrics.2014.1906

12. Taylor V. Correct Umbilical Cord "Milking" Technique. Australian Placental Transfusion Study, West Mead Hospital. Sydney,NSW. Available online at: http://www.videos. Med.usyd.edu.au/unitube/videos/file19.

13. Yadav AK, Upadhyay A, Gothwal S, Dubey K, Mandal U, Yadav CP. Comparison of three types of intervention to enhance placental redistribution in term newborns: randomized control trial. J Perinatol. (2015) 35:720-4. doi: $10.1038 /$ jp. 2015.65 the final version of the manuscript. $\mathrm{MD}$ and $\mathrm{AL}$ wrote the first draft of paragraphs on term newborns, twins, and gas analysis. BP wrote the first draft of paragraphs on late preterms, pregnancy with feto-maternal alloimmunization, HIV-positive pregnancy and contraindications. SF contributed to writing the first draft of the paragraph on congenital heart disease. PS contributed to writing the first draft on cord blood banking. SP contributed to writing the first draft on preterm $<34$ weeks and together with SG and BP conceptualize the Flow-chart. All authors approved the final version.

\section{ACKNOWLEDGMENTS}

The Authors would thank Daniele Merazzi for his helpful revision of methodology; Daniele Trevisanuto, Antonello Del Vecchio, Gaetano Chirico, Giuseppe Battagliarin, Tullia Todros, Davide de Vita, Maurizio Silvestri, Elsa Viora, Marilisa Coluzzi, Iolanda Rinaldi for their revisions of the Italian version of the document.
14. McDonald SJ, Middleton P, Dowswell T, Morris PS. Effect of timing of umbilical cord clamping of term infants on maternal and neonatal outcomes. Cochrane Database of Syst Rev. (2013) 7:CD004074. doi: 10.1002/14651858.CD004074.pub3

15. Hutton EK, Hassan ES. Late vs. early clamping of the umbilical cord in full-term neonates systematic review and meta-analysis of controlled trials. JAMA (2007) 297:1241-52. doi: 10.1001/jama.297.11.1241

16. Rabe EK, Hassan ES. Late vs. early clamping of the umbilical cord in full-term neonates: systematic review and meta-analysis of controlled trials. JAMA (2007) 2297: 1241-52.

17. Ghavam S, Batra D, Mercer J, Kugelman A, Hosono S, Oh W, et al. Effects of placental transfusion in extremely low birthweight infants: metaanalysis of long- and short-term outcomes. Transfusion (2014) 54:1192-8. doi: 10.1111/trf.12469

18. Backes CH, Rivera BK, Haque U, Bridge JA, Smith CV, Hutchon DJ, et al. Placental transfusion strategies in very preterm neonates: a systematic review and meta-analysis. Obstet Gynecol. (2014) 124:47-56. doi: 10.1097/AOG.0000000000000324

19. Mercer JS, Vohr BR, McGrath MM, Padbury JF, Wallach M, Oh W. Delayed cord clamping in very preterm infants reduces the incidence of intraventricular hemorrhage and late-onset sepsis: a randomized, controlled trial. Pediatrics (2006) 117:1235-42. doi: 10.1542/peds.2005-1706

20. Oh W, Fanaroff AA, Carlo WA, Donovan EF, McDonald SA, Poole WK et al. Effects of delayed cord clamping in very-low-birth-weight infants. $J$ Perinatol. (2012)31(Suppl. 1):S68-71. doi: 10.1038/jp.2010.186

21. Hosono S, Mugishima H, Fujita H, Hosono A, Minato M, Okada T, et al. Umbilical cord milking reduces the need for red cell transfusions and improves neonatal adaptation in infants born at less than 29 weeks' gestation: a randomized controlled trial. Arch Dis Child Fetal Neonatal Ed. (2008) 93:F14-9. doi: 10.1136/adc.2006.108902

22. Sommers R, Stonestreet BS, Oh W, Laptook A, Yanowitz TD, Raker C, et al. Hemodynamic effects of delayed cord clamping in premature infants. Pediatrics (2012) 129:e667-72. doi: 10.1542/peds.2011-2550

23. Patel S, Clark EA, Rodriguez CE, Metz TD, Abbaszadeh M, Yoder BA. Effect of umbilical cord milking on morbidity and survival in extremely low gestational age neonates. Am J Obstet Gynecol. (2014) 211:519.e1-7. doi: 10.1016/j.ajog.2014.05.037

24. Tarnow-Mordi W, Morris J, Kirby A, Robledo K, Askie L, Brown R, et al. Delayed versus immediate cord clamping in preterm infants. N Engl J Med. (2017) 377:2445-55. doi: 10.1056/NEJMoa1711281 
25. Fogarty M, Osborn DA, Askie L, Seidler AL, Hunter K, Lui K, et al. Delayed versus early umbilical cord clamping for preterm infants: a systematic review and meta-analysis. Am J Obstet Gynecol. (2017) 218:1-18. doi: 10.1016/j.ajog.2017.10.231

26. Andersson $\mathrm{O}$, Lindquist $B$, Lindgren $M$, Stjemqvist $K$, Domellof $M$, Hellstrom-Westas L. Effect of delayed cord clamping on neurodevelopment at 4 years of age a randomized clinical trial. JAMA Pediatr. (2015) 169:631-8. doi:10.1001/jamapediatrics.2015.0358

27. Katheria A, Garey D, Truong G, Akshoomoff N, Steen J, Maldonado M, et al. A randomized clinical trial of umbilical cord milking vs. delayed cord clamping in preterm infants: neurodevelopmental outcomes at 22-26 months of corrected age. J Pediatr. (2018) 194:76-80. doi: 10.1016/j.jpeds.2017.10.037

28. Bhatt S, Alison BJ, Wallace EM, Crossley KJ, Gill AW, Kluckow M, et al. Delaying cord clamping until ventilation onset improves cardiovascular function at birth in preterm lambs. J Physiol. (2013) 591:2113-26. doi: 10.1113/jphysiol.2012.250084

29. Polglase GR, Dawson JA, Kluckow M, Gill AW, Davis PG, Te Pas AB, et al. Ventilation onset prior to umbilical cord clamping (physiological-based cord clamping) improves systemic and cerebral oxygenation in preterm lambs. PLoS ONE (2015) 10:e0117504. doi: 10.1371/journal.pone.0117504

30. WHO. Guideline: Delayed Umbilical Cord Clamping for Improved Maternal and Infant Health and Nutrition Outcomes. Geneva: WHO (2014).

31. Wyllie J, Bruinenberg J, Roehr CC, Rüdiger M, Trevisanuto D, Urlesberger B. European Resuscitation Council Guidelines for Resuscitation 2015: Section 7. Resuscitation and support of transition of babies at birth. Resuscitation (2015) 95:249-63. doi: 10.1016/j.resuscitation.2015.07.029

32. Wyckoff MH, Aziz K, Escobedo MB, Kapadia VS, Kattwinkel J, Perlman JM, et al. Part 13: Neonatal Resuscitation 2015 American Heart Association Guidelines update for cardiopulmonary resuscitation and emergency cardiovascular care. Circulation (2015) 132:S543-60. doi: 10.1161/CIR.0000000000000267

33. Committee on Obstetric Practice. Committee Opinion No. 684: delayed umbilical cord clamping after birth. Obstet Gynecol. (2017) 129:e5-10. doi: 10.1097/AOG.0000000000001860

34. Committee on Obstetric Practice, American College of Obstetricians and Gynecologists. Committee Opinion No.543: timing of umbilical cord clamping after birth. Obstet Gynecol. (2012) 120:1522-6. doi: 10.1097/00006250-201212000-00045

35. Katheria AC, Truong G, Cousins L, Oshiro B, Finer NN. Umbilical cord milking versus delayed cord clamping in preterm infants. Pediatrics (2015) 136:61-9. doi: 10.1542/peds.2015-0368

36. Nevill E, Meyer MP. Effect of delayed cord clamping (DCC) on breathing and transition at birth in very preterm infants. Early Hum Dev (2015) 91:407-11. doi: 10.1016/j.earlhumdev.2015.04.013

37. Jelin AC, Kuppermann M, Erickson K, Clyman R, Schulkin J. Obstetricians' attitudes and beliefs regarding umbilical cord clamping. J Matern Fetal Neonatal Med. (2014) 27:1457-61. doi: 10.3109/14767058.2013.864275

38. Perrone B, Ghirardello S for the "Italian Survey on Placental Transfusion Group”. Placental transfusion strategies in italy: a nationwide survey of tertiary-care delivery wards. Am J Perinatol. (2017) 34:722-8. doi: 10.1055/s-0036-1597995

39. Backes CH, Huang H, Iams JD, Bauer JA, Giannone PJ. Timing of umbilical cord clamping among infants born at 22 through 27 weeks' gestation. $J$ Perinatol. (2016) 36:35-40. doi: 10.1038/jp.2015.117

40. Ersdal HL, Linde J, Mduma E, Auestad B, Perlman J. Neonatal outcome following cord clamping after onset of spontaneous respiration. Pediatrics (2014) 134:265-72. doi: 10.1542/peds.2014-0467

41. Katheria A, Poeltler D, Durham J, Steen J, Rich W, Arnell K, et al. Neonatal resuscitation with an intact cord: a randomized clinical trial. J Pediatr. (2016) 178:75-80. doi: 10.1016/j.jpeds.2016.07.053

42. Kattwinkel J, Perlman JM, Aziz K, Colby C, Fairchild K, Gallagher J, et al. Part 15: neonatal resuscitation: 2010 American Heart Association guidelines for cardiopulmonary resuscitation and emergency cardiovascular care. Circulation (2010) 122:S909-19. doi: 10.1161/CIRCULATIONAHA.110.971119

43. GRADE Working Group (2004). Grading quality of evidence and strenght of recommendations. BMJ (2004) 328:1490-4. doi: 10.1136/bmj.328.745 4.1490
44. Andrews JC, Guyatt G, Oxman AD, Alderson P, Dahm P, Falck-Ytter Y, et al. GRADE guidelines: 14. Going from evidence to recommendation-the significance and presentations of recommendations. J Clin Epidemiol. (2013) 66:719-25. doi: 10.1016/j.jclinepi.2012.03.013

45. Andrews JC, Schunemann HJ, Oxman AD, Pottie K, Meerpohl JJ, Coello PA, et al. GRADE guidelines: 15. Going from evidence to recommendation-determinants of a recommendation's direction and strength. J Clin Epidemiol. (2013) 66:726-35. doi: 10.1016/j.jclinepi.2013.02. 003

46. Andersson O, Hellström-Westas L, Andersson D, Domellöf M. Effect of delayed versus early umbilical cord clamping on neonatal outcomes and iron status at 4 months: a randomized controlled trial. BMJ (2011) 343:d7157. doi: 10.1136/bmj.d7157

47. Chaparro CM, Neufeld LM, Tena Alavez G, Eguia-Líz Cedillo R, Dewey KG. Effect of timing of umbilical cord clamping on iron status in Mexican infants: a randomized controlled trial. Lancet (2006) 367:19972004. doi: 10.1016/S0140-6736(06)68889-2

48. Ashish KC Rana, RN, Målqvist M, Ranneberg J, Subedi K, Andersson O. Effects of delayed umbilical cord clamping vs. early clamping on anemia in infants at 8 and 12 months a randomized clinical trial. JAMA Pediatr. (2017) 171:264-70. doi: 10.1001/jamapediatrics.2016.3971

49. Vain NE, Satragno DS, Gorenstein AN, Gordillo JE, Berazategui JP, Alda MG, et al. Effect of gravity on volume of placental transfusion: a multicentre, randomized, non-inferiority trial. Lancet (2014) 384:235-40. doi: 10.1016/S0140-6736(14)60197-5

50. Mansaray A, Yetman R, Berens P. Effect of delayed cord clamping above versus below the perineum on neonatal hematocrit: a randomized controlled trial. Breastfeed Med. (2015) 10:464-7. doi: 10.1089/bfm.2015.0109

51. Mercer JS, Erickson-Owens DA, Collins J, Barcelos MO, Parker AB, Padbury JF. Effects of delayed cord clamping on residual placental blood volume, hemoglobin and bilirubin levels in term infants: a randomized controlled trial. J Perinatol. (2017) 37:260-4. doi: 10.1038/jp.2016.222

52. Zhou YB, Li HT, Zhu LP, Liu JM. Impact of cesarean section on placental transfusion and iron-related hematological indices in term neonates: a systematic review and meta-analysis. Placenta (2014) 35:1-8. doi: 10.1016/j.placenta.2013.10.011

53. Kleinberg F, Dong L, Phibbs RH. Cesarean section prevents placenta-toinfant transfusion despite delayed cord clamping. Am J Obstet Gynecol. (1975) 121:66-70. doi: 10.1016/0002-9378(75)90977-1

54. Ogata ES, Kitterman JA, Kleinberg F, Dong L, Willis M, Mates J, et al. The effect of time of cord clamping and maternal blood pressure on placental transfusion with cesarean section. Am J Obstet Gynecol. (1977) 128:197-200.

55. Glasser L, Sutton N, Schmeling M, Machan JT. A comprehensive study of umbilical cord blood cell developmental changes and reference ranges by gestation, gender and mode of delivery. J Perinatol. (2015) 35:469-75. doi: $10.1038 /$ jp. 2014.241

56. Ceriani Cernadas JM, Carroli G, Pellegrini L, Otan o L, Ferreira M, Ricci C, et al. The effect of timing of cord clamping on neonatal venous hematocrit values and clinical outcome at term: a randomized, controlled trial. Pediatrics (2006) 117:e779-85. doi: 10.1542/peds.2005-1156

57. Ertekin AA, Nihan Ozdemir N, Sahinoglu Z, Gursoy T, Erbil N, Kaya E. Term babies with delayed cord clamping: an approach in preventing anemia. J Matern Fetal Neonatal Med. (2016) 29:2813-6. doi: 10.3109/14767058.2015.1105951

58. Andersson O, Hellström-Westas L, Domellöf M. Elective cesarean: does delay in cord clamping for $30 \mathrm{~s}$ ensure sufficient iron stores at 4 months of age? A historical cohort control study. BMJ Open (2016) 6:e012995. doi: 10.1136/bmjopen-2016-012995

59. Erickson-Owens DA, Mercer JS, Oh W. Umbilical cord milking in term infants delivered by cesarean section: a randomized controlled trial. J Perinatol. (2012) 32: 580-4. doi: 10.1038/jp.20 11.159

60. Upadhyay A, Gothwal S, Parihar R, Garg A, Gupta A, Chawla D, et al. Effect of umbilical cord milking in term and near-term infants: randomized control trial. Am J Obstet Gynecol. (2013) 208:120.e1-6. doi: 10.1016/j.ajog.2012.10.884

61. Bora R, Akhtar SS, Venkatasubramaniam A, Wolfson J, Rao R. Effect of 40$\mathrm{cm}$ segment umbilical cord milking on hemoglobin and serum ferritin at 
6 months of age in full-term infants of anemic and non-anemic mothers. $J$ Perinatol. (2015) 35:832-6. doi: 10.1038/jp.2015.92

62. Jaiswal P, Upadhyay A, Gothwal S, Singh D, Dubey K, Garg A, et al. Comparison of two types of intervention to enhance placental redistribution in term infants: randomized control trial. Eur J Pediatr. (2015) 174:1159-67. doi: 10.1007/s00431-015-2511-y

63. McAdams RM, Fay E, Delaney S. Whole blood volumes associated with milking intact and cut umbilical cords in term newborns. J Perinatol. (2018) 38:245-50. doi: 10.1038/s41372-017-0002-x

64. Ultee CA, van der Deure J, Swart J, Lasham C, van Baar AL. Delayed cord clamping in preterm infants delivered at 34-36 weeks' gestation: a randomized controlled trial. Arch Dis Child Fetal Neonatal Ed. (2008) 93:F20-3. doi: 10.1136/adc.2006.100354

65. Strauss RG, Mock D, Johnson K, Mock N, Cress G, Knosp L, et al. Circulating RBC volume, measured with biotinylated RBCs, is superior to the Hct to document the hematologic effects of delayed versus immediate umbilical cord clamping in preterm neonates. Transfusion (2003) 43:116872. doi: 10.1046/j.1537-2995.2003.00454.x

66. Salae R, Tanprasertkul C, Somprasit C, Bhamarapravatana K, Suwannarurk K. Efficacy of delayed versus immediate cord clamping in late preterm newborns following normal labor: a randomized control trial. J Med Assoc Thai (2016) 99:S159-65.

67. Ranjit T, Nesargi S, Rao PN, Sahoo JP, Ashok C, Chandrakala BS, Bhat S. Effect of early versus delayed cord clamping on hematological status of preterm infants at $6 \mathrm{wk}$ of age. Indian J Pediatr (2015) 82:29-34. doi: 10.1007/s12098-013-1329-8

68. Kugelman A, Borenstein-Levin L, Riskin A, Chistyakov I, Ohel G, Gonen R, Bader D. Immediate versus Delayed umbilical cord clamping in premature neonates born < 35 weeks: a prospective, randomized, controlled study. Am J Perinatol. (2007) 24:307-16. doi: 10.1055/s-2007-981434

69. Hofmeyer GJ, Gobetz L, Bex PJM, Van Der Griendt M, Nikodem CV, Skapinker R. Periventricular/Intraventricular hemorrhage following early and delayed umbilical cord clamping: a randomized trial. Online J Curr Clin Trials (1993).

70. Jelin AC, Zlatnik MG, Kuppermann M, Gregorich SE, Nakagawa S, Clyman R. Clamp late and maintain perfusion (CLAMP) policy: delayed cord clamping in preterm infants. J Matern Fetal Neonatal Med. (2016) 29:1705-9. doi: 10.3109/14767058.2015.1061496

71. Strauss RG, Mock DM, Johnson KJ, Cress GA, Burmeister LF, Zimmerman $\mathrm{MB}$, et al. A randomized clinical trial comparing immediate versus delayed clamping of the umbilical cord in preterm infants: shortterm clinical and laboratory endpoints. Transfusion (2008) 48:658-65. doi: 10.1111/j.1537-2995.2007.01589.x

72. Datta V, Kumar A, Yadav R. A randomized controlled trial to evaluate the role of brief delay in cord clamping in preterm neonates (34-36 weeks) on short-term neurobehavioural outcome. J Trop Pediatr. (2017) 63:418-424. doi: 10.1093/tropej/fmx004

73. Kumar B, Upadhyay A, Gothwal S, Jaiswal V, Joshi P, Dubey K. Umbilical cord milking and hematological parameters in moderate to late preterm neonates: a randomized controlled trial. Indian Pediatr. (2015) 52:753-7. doi: $10.1007 /$ s13312-015-0711-1

74. Niermeyer S. Ventilation remains the key to neonatal resuscitation. J Pediatr. (2016) 171:8-10. doi: 10.1016/j.jpeds.2015.12.080

75. Lee ACC, Cousens S, Wall SN, Niermeyer S, Darmstadt GL, Carlo WA, et al. Neonatal resuscitation and immediate newborn assessment and stimulation for the prevention of neonatal deaths: a systematic review, meta-analysis and Delphi estimation of mortality effect. BMC Public Health (2011) 11:S12. doi: 10.1186/1471-2458-11-S3-S12

76. Msemo G, Massawe A, Mmbando D, Rusibamayila N, Manji K, Kidanto $\mathrm{KL}$, et al. Newborn mortality and fresh stillbirth rates in tanzania after helping babies breathe training. Pediatrics (2013) 131:353-60. doi: 10.1542/peds.2012-1795

77. Mercer JS, Erickson-Owens DA, Vohr BR, Tucker RJ, Parker AB, Oh W, et al. Effects of placental transfusion on neonatal and 18 month outcomes in preterm infants: a randomized controlled trial. J Pediatr. (2016) 168:50-5. doi: 10.1016/j.jpeds.2015.09.068

78. Rabe H, Jewison A, Alvarez RF, Crook D, Stilton D, Bradley R, et al. Milking compared with delayed cord clamping to increase placental transfusion in preterm neonates: a randomized controlled trial. Obstet Gynecol. (2011) 117:205-11. doi: 10.1097/AOG.0b013e3181fe46ff

79. Rabe H, Sawyer A, Amess P, Ayers S; Brighton Perinatal Study Group. Neurodevelopmental outcomes at 2 and 3.5 years for very preterm babies enrolled in a randomized trial of milking the umbilical cord versus delayed cord clamping. Neonatology (2016) 109:113-9. doi: 10.1159/0004 41891

80. Christensen RD, Baer VL, Gerday E, Sheffield MJ, Richards DS, Shepherd JG, et al. Whole-blood viscosity in the neonate: effects of gestational age, hematocrit, mean corpuscular volume and umbilical cord milking. $J$ Perinatol. (2014) 34:16-21. doi: 10.1038/jp.2013.112

81. Garabedian C, Rakza T, Drumez E, Poleszczuk M, Ghesquiere L, Wibaut B, et al. Benefits of delayed cord clamping in red blood cell alloimmunization. Pediatrics (2016) 137:e20153236. doi: 10.1542/peds.201 5-3236

82. Panel on Treatment of HIV-Infected Pregnant Women and Prevention of Perinatal Transmission. Recommendations for Use of Antiretroviral Drugs in Pregnant HIV-1-Infected Women for Maternal Health and Interventions to Reduce Perinatal HIV Transmission in the United States. Available online at: http://aidsinfo.nih.gov/contentfiles/lvguidelines/PerinatalGL.pdf. Accessed 12 June 2016.

83. WHO. Recommendations for the Prevention and Treatment of Postpartum Hemorrhage. Geneva: WHO (2012).

84. Pogliani L, Erba P, Nannini P, Giacomet V, Zuccotti GV. Effects and safety of delayed versus early umbilical cord clamping in newborns of HIV-infected mothers. J Matern Fetal Neonatal Med. (2017) 16:1-4. doi: 10.1080/14767058.2017.1387896

85. ACOG Committee Opinion No. 751: Labor and Delivery Management of Women With Human Immunodeficiency Virus Infection. Committee on Obstetric Practice; HIV Expert Work Group. Obstet Gynecol. (2018) 132: e131-7. doi: 10.1097/AOG.00000000000 02820

86. Lopriore E, Sueters M, Middeldorp JM, Vandenbussche FP, Walther FJ. Haemoglobin differences at birth in monochorionic twins without chronic twin-to-twin transfusion syndrome. Prenat Diagn (2005) 25:844-50. doi: 10.1002/pd.1175

87. Verbeel K, Zhao DP, te Pas AB, Middeldorp JM, Hooper SB, Oepkes D, et al. Hemoglobin differences in uncomplicated monochorionic twins in relation to birth order and mode of delivery. Twin Res and Hum Genet. (2016) 19:241-5. doi: 10.1017/thg.2016.23

88. Verbeek L, Zhao DP, Middeldorp M, Oepkes D, Hooper SB, Te Pas AB, et al. Haemoglobin discordances in twins: due to differences in timing of cord clamping? Arch Dis Child Fetal Neonatal (2017) 102:F423-8. doi: 10.1136/archdischild-2016-311822

89. Mc. Donnel M, Henderson-Smart DJ. Delayed umbilical cord clamping in preterm infants: a feasibility study J Paediatr Child Health (1997) 33:308-10. doi: 10.1111/j.1440-1754.1997.tb01606.x

90. Backes $\mathrm{CH}$, Huang $\mathrm{H}$ et al. Early versus delayed umbilical cord clamping in infants with congenital heart disease: a pilot, randomized, controlled trial. J Perinatol. (2015) 35:826-31. doi: 10.1038/jp. 2015.89

91. Sanapo L, Moon-Grady AJ, Donofrio MT. Perinatal and delivery management of infants with congenital heart disease. Clin Perinatol. (2016) 43:55-71. doi: 10.1016/j.clp.2015.11.004

92. Armstrong L, Stenson BJ. Use of umbilical cord blood gas analysis in the assessment of the newborn. Arch Dis Child Fetal Neonatal Ed. (2007) 92:F430-4. doi: 10.1136/adc.2006.099846

93. Andersson O, Hellstrom-Westas L, Andersson D, Clausen J, Domello M. Effects of delayed compared with early umbilical cord clamping on maternal postpartum hemorrhage and cord blood gas sampling: a randomized trial. Acta Obstet Gynecol Scand. (2013) 92: 567-74. doi: 10.1111/j.1600-0412.2012.01530.x

94. Perlman JM. Intrapartum hypoxic-ischemic cerebral injury and subsequent cerebral palsy: medicolegal issues. Pediatrics (1997) 99: 851-9. doi: 10.1542 /peds.99.6.851

95. ACOG Committee on Obstetric Practice: ACOG Committee Opinion No. 348, November 2006: Umbilical cord blood gas and acid-base analysis. Obstet Gynecol. (2006) 108:1319-22. 
96. South Australian Perinatal Practice Guidelines: Umbilical Cord Blood Gas Sampling (2014).

97. NICE. Clinical Guideline $n^{\circ} 190$ Intrapartum Care: Care for Healthy Woman and Their Baby During Childbirth (2014).

98. Wiberg, Källén K, Olofsson P. Delayed umbilical cord clamping at birth has effects on arterial nd venous blood gases and lactate concentrations. BJOG (2008) 115:697-703. doi: 10.1111/j.1471-0528.2008.01708.x

99. Valero J, Desantes D, Perales-Puchalt A, Rubio J, Diago Almela VJ, Perales A. Effect of delayed umbilical cord clamping on blood gas analysis. Eur J Obstet Gynecol Reprod Biol. (2012) 162:21-3. doi: 10.1016/j.ejogrb.2012.01.020

100. De Paco C, Florido J, Garrido M, Prados S, Navarrete L. Umbilical cord blood acid-base and gas analysis after early versus delayed cord clamping in neonates at term. Arch Gynecol Obstet. (2011) 283:1011-4. doi: $10.1007 /$ s00404-010-1516-z

101. Di Tommaso M, Seravalli V, Martini I, La Torre P, Dani C. Blood gas values in clamped and unclamped umbilical cord at birth. Early Hum Dev. (2014) 90:523-5. doi: 10.1016/j.earlhumdev.2014.03.010

102. Rocha V, Gluckman E. Eurocord and European Blood and Marrow Transplant Group. Clinical use of umbilical cord blood hematopoietic stem cells. Biol Blood Marrow Transplant. (2006) 12:34-41. doi: 10.1016/j.bbmt.2005.09.006

103. Ballen KK, Gluckman E, Broxmeyer HE. Umbilical cord blood transplantation: the first 25 years and beyond. Blood 122:491-8. doi: 10.1182/blood-2013-02-453175

104. Barker JN, Scaradavou A, Stevens CE. Combined effect of total nucleated cell dose and HLA match on transplantation outcome in 1061 cord blood recipients with hematologic malignancies Blood (2011) 115:1843-9. doi: 10.1182/blood-2009-07-231068

105. Querol S, Gomez SG, Pagliuca A, Torrabadella M, Madrigal JA. Quality rather than quantity: the cord blood bank dilemma. Bone Marrow Transplant. (2010) 45:970-8. doi: 10.1038/bmt.2010.7

106. Page KM, Mendizabal A, Betz-Stablein B, Wease S, Shoulars K, Gentry T, et al. Optimizing donor selection for public cord blood banking: influence of maternal, infant, and collection characteristics on cord blood unit quality. Transfusion (2014) 54:340-52. doi: 10.1111/trf.12257

107. Lawless T, Mostert K, Oppenheimer L, Walker M, Petraszko T, Elmoazzen H. Delayed clamping of the umbilical cord after delivery and implications for public cord blood banking. Transfusion (2016) 56:662-5. doi: 10.1111/trf.13424

108. Armson BA, Allan DS, Casper RF; Cord Blood Banking Working Group. Umbilical cord blood: counselling, collection, and banking.
J Obstet Gynaecol Can. (2015) 37:832-46. doi: 10.1016/S1701-2163(15) 30157-2

109. Frändberg S, Waldner B, Konar J, Rydberg L, Fasth A, Holgersson J. Highquality cord blood banking is feasible with delayed clamping practices. The eight-year experience and current status of the national Swedish Cord Blood Bank. Cell Tissue Bank (2016) 17:439-48. doi: 10.1007/s10561-0169565-6

110. ACOG Committee Opinion No. 648: Umbilical Cord Blood Banking. Obstet Gynecol. (2015) 126:e127-9. doi: 10.1097/AOG.00000000000 01212

111. Templeton A, Braude P. Umbilical cord blood banking and the RCOG. Lancet (2007) 31:1077. doi: 10.1016/S0140-6736(07) 60515-7

112. American Academy of Pediatrics: policy statement on Cord Blood Banking for Potential Future Transplantation. Pediatrics (2007) 119:165-71. doi: 10.1542/peds.2006-2901

113. Cesari E, Ghirardello S, Brembilla G, Svelato A, Ragusa A. Clinical features of fatal shoulder dystocia: the hypovolemic shock hypothesis. Med Hypotheses (2018) 118:139-41. doi: 10.1016/j.mehy.2018. 07.006

114. Rosenberg A. The IUGR newborn. Semin Perinatol. (2008) 32:219-24. doi: 10.1053/j.semperi.2007.11.003

115. Lausman A, Kingdom J. Maternal Fetal Medicine Committee. Intrauterine growth restriction: screening, diagnosis, and management. J Obstet Gynaecol Can (2013) 35:741-8. doi: 10.1016/S1701-2163(15)3 0865-3

116. Sankar MJ, Agarwal R, Deorari A, Paul VK. Management of polycythemia in neonates. Indian $J$ Pediatr. (2010) 77:1117-21. doi: $10.1007 / \mathrm{s} 12098-010-0177-\mathrm{z}$

Conflict of Interest Statement: The authors declare that the research was conducted in the absence of any commercial or financial relationships that could be construed as a potential conflict of interest.

Copyright (C) 2018 Ghirardello, Di Tommaso, Fiocchi, Locatelli, Perrone, Pratesi and Saracco. This is an open-access article distributed under the terms of the Creative Commons Attribution License (CC BY). The use, distribution or reproduction in other forums is permitted, provided the original author(s) and the copyright owner(s) are credited and that the original publication in this journal is cited, in accordance with accepted academic practice. No use, distribution or reproduction is permitted which does not comply with these terms. 